\title{
Aurora: uma obra de transição no conjunto dos escritos de Nietzsche
}

\author{
Geraldo Dias*
}

\begin{abstract}
Resumo: Neste artigo, temos por objetivo analisar a hipótese de que o livro Aurora, no conjunto dos escritos de Friedrich Nietzsche, apresenta uma filosofia transitória. Nesse sentido, faremos ver que, justamente por causa de seu caráter transitório Aurora tem sido tão subestimada e obscurecida, principalmente quando comentada não a partir de seu quadro teórico transitivo, mas a partir de conceitos e projetos posteriores. Palavras-chaves: Aurora - transição - pré-genealogia - sentimento de potência - transmutação da moral
\end{abstract}

\section{I-Introdução}

Atualmente Aurora (Morgenröte) tem suscitado um interesse renovado na pesquisa internacional sobre Nietzsche. Mas não foi sempre assim, dentre as obras de Nietzsche, Aurora foi até pouco tempo atrás bastante negligenciada e até mesmo considerada obscura por parte de alguns comentadores. Isso tem ocorrido sempre que os comentadores interpretam as reflexões de Nietzsche nessa sua obra à luz de conceitos, projetos e doutrinas filosóficas posteriores a sua composição. E não é raro nos depararmos com leituras que tendem a desconsiderar seu caráter transitório, e, por isso mesmo, acabam por obscurecê-la.

\footnotetext{
* Mestre em Filosofia pela Universidade Federal de São Paulo (UNIFESP), São Paulo, Brasil. Endereço eletrônico: ge.pdias@hotmail.com.
} 
Dias, G.

Para nos contrapor a essa literatura que tende a submeter $\mathrm{Au}$ rora à filosofia tardia de Nietzsche, pretendemos analisá-la em seu tempo próprio, única maneira de verificar em que sentido as ideias transitivas presentes no livro, de fato, contribuíram para viabilizar a construção de conceitos e projetos posteriores, tais como genealogia, vontade de potência e transvaloração de todos os valores, mas sem subsumi-la a tais noções ${ }^{1}$. Nossa dificuldade consiste em avaliar em que sentido a associação entre Aurora e o projeto da transvaloração favorece a uma compreensão da obra e em que sentido apenas a obscurece. A partir disso, defenderemos que Aurora - a despeito de alguns comentadores - não faz parte do projeto da transvaloração de todos os valores.

Para encontrar seu lugar no contexto da filosofia nietzschiana, interpretaremos o livro como um momento de transição no pensamento de Nietzsche, no sentido de construção das condições de possibilidade teóricas que lhe permitirão mais tarde chegar à concepção de uma transvaloração de todos os valores vigentes até então no ocidente cristão. Com isso, queremos mostrar que Aurora é portadora de uma filosofia transitória, que ela apresenta elementos filosóficos decisivos para a consolidação de ferramentas teóricas necessárias à realização do projeto da transvaloração no horizonte da filosofia tardia de Nietzsche. Enfim, defender que nesse livro Nietzsche começa a criar um quadro teórico que lhe possibilitará desenvolver temas centrais de sua filosofia.

De fato, pode-se dizer que em Aurora Nietzsche construiu um quadro teórico filosófico que, mais tarde, irá possibilitar o despontar de novos projetos. Em outras palavras, para expor nossa hipótese de que Aurora apresenta uma filosofia transitória no pensamento de Nietzsche, procuraremos na obra mesma encontrar

1 Neste artigo, recorremos primeiramente à tradução de Rubens Rodrigues Torres Filho para o volume Nietzsche - Obras incompletas (São Paulo: Nova Cultural, 1996 (Coleção "Os Pensadores")). E, em segundo lugar, adotamos a tradução de Paulo César de Souza, publicada pela Cia das Letras, e que será indicada pelas siglas PCS. 
aquela formação dos seus elementos filosóficos operatórios primordiais transitivos daquilo que somente mais tarde será característico na filosofia nietzschiana: seu procedimento de investigação dos valores, sua hipótese para avaliá-los e seu projeto de transvalorá-los.

E assim, logo no início do artigo iremos tratar do renascimento de Aurora nos últimos decênios. Em seguida, dissertaremos a respeito do projeto de Nietzsche em Aurora. Depois, exporemos a hipótese de que há em Aurora um quadro teórico de transição metodológica, este será denominado de “pré-genealogia". Este procedimento metodológico de investigação é empregado no livro para analisar a gênese da moral. A aplicação desse raciocínio nos mostra o despontar de um elemento filosófico em operação que possibilitará o surgimento futuro de um novo procedimento metodológico na filosofia nietzschiana.

Em seguida, faremos ver que Nietzsche desenvolve em Aurora um critério com o qual poderá realizar uma análise crítica da moral. Com ele o filósofo construía uma importante base teórica para o seu pensamento posterior, na medida em que esse critério denominado por ele de sentimento de potência (Gefühl der Macht) torna-se um instrumento teórico balizador dos preconceitos morais, a instância capaz de sintetizar e manifestar a pluralidade dos impulsos constituintes da moral. Nessa direção, mostraremos que Aurora apontava para um quadro teórico de transição na filosofia de Nietzsche, que, neste caso, irá desembocar na doutrina da vontade de potência (Wille zur Macht).

Por fim, mais um elemento filosófico de transição poderá ser estabelecido ao considerarmos que Aurora aborda a ideia de que o cristianismo é uma espécie de transmutação (Verwandlung) moral da eticidade do costume. Por conseguinte, concluiremos que Nietzsche caminhava a passos largos, a partir da percepção dessa transmutação ocorrida, para a formulação de seu projeto da transvaloração de todos os valores (Umwerthung aller Werthe). 
Dias, G.

\section{II - O renascimento de Aurora}

Dentre as obras de Nietzsche, Aurora tem sido, de certa forma, bastante negligenciada e até mesmo considerada obscura por parte de alguns comentadores ${ }^{2}$. Por outro lado, nos últimos decênios esse livro despertou o interesse dos pesquisadores da filosofia nietzschiana. Novas traduções foram realizadas, em língua francesa, italiana, espanhola, portuguesa, inglesa; encontros internacionais foram dedicados exclusivamente a sua discussão. Entre as pesquisas realizadas sobre Aurora nesses últimos decênios, dialogaremos com algumas que tendem a desconsiderar o seu aspecto de filosofia transitória, com isso mostraremos o quanto o livro fica prejudicado e/ou obscurecido.

A partir desse novo renascimento, Maudemarie Clark considera que "[o] livro (...) marca o início do projeto filosófico central de Nietzsche: a transvaloração de todos os valores, uma crítica completa de longo curso da própria moralidade" ${ }^{3}$. Clark acredita ainda que em Aurora Nietzsche "aborda 'a problemática da origem dos valores morais', a questão a que ele retorna em Para além de bem e mal (especialmente a seção 260) e mais comumente em a Genealogia". Enfim, a comentadora considera que Aurora "é o primeiro livro em que se desenvolvem de maneira substancial temas que marcam o Nietzsche 'maduro', por exemplo, a sua crítica da visão convencional de ação humana, bem como seu desenvolvimento de uma concepção 'naturalista' das pessoas". E assim pretende ler

2 "Ao contrário da maioria de seus outros trabalhos, [Aurora] têm sido tristemente negligenciada durante o renascimento de Nietzsche nas últimas três décadas (...)”, CLARK, M. Daybreak: thoughts on the prejudices of morality. Trad. R. J. Hollingdale. Cambridge University Press. Introduction, 1997, p. vii. Realmente, em Aurora Nietzsche se empenhou "numa luta contra a moral da renúncia de si" (EH/EH, Morgenröte, 2 KSA 6.331), porém, este seu trabalho não foi bem acolhido nem mesmo por seus amigos mais próximos. Erwin Rohde, por exemplo, nem sequer chegou a agradecer-lhe o recebimento da obra, nem respondeu à carta que Nietzsche lhe enviara.

3 CLARK, M. Daybreak: thoughts on the prejudices of morality. Trad. R. J. Hollingdale. Cambridge University Press. Introduction, 1997, p. VIII.

234 | Cad. Nietzsche, São Paulo, n. 34 - vol. I, p. 231-254, 2014. 
e/ou interpretar Aurora não a partir dela mesma, mas sempre à luz de noções e obras bem posteriores.

Ao reconhecer Aurora como a obra mais subestimada de Nietzsche, Clark também considera um grave erro negligenciar esse livro. Nesse sentido, tenta apresentar e definir o cenário intelectual (contexto histórico e filosófico) em que o livro é concebido por Nietzsche. A fim de encontrar o lugar de Aurora no corpus nietzschiano, a autora limita-se a fazer uma pesquisa histórico-biográfica da obra, em vez de desvendar as reflexões e os objetivos do filósofo presentes em seu livro e, a partir daí, confrontá-los com projetos posteriores.

Nessa direção, vemos que Clark não problematiza as ideias presentes em Aurora e, menos ainda, em sua relação com o projeto da transvaloração. Tanto é assim que para Clark Aurora já apresentaria uma investigação a respeito do problema do valor dos valores morais, o que, todavia, se mostra um tanto improvável, pois o objetivo do autor no livro fora refletir sobre a gênese da moral e seus preconceitos, procurando alcançar deles certo desprendimento e liberação ${ }^{4}$. A nosso ver, Aurora traz elementos teóricos e temas que serão, sem dúvida, aprofundados posteriormente, possibilitando a Nietzsche transitar para aquilo que caracteriza a sua filosofia tardia. Tal livro, porém, diferentemente das posições de Clark, não apresenta de maneira substancial qualquer elemento filosófico que possa ser enquadrado no âmbito de sua filosofia madura sem alterações significativas.

4 Como afirma Scarlett Marton: "Aurora apresentava como subtítulo 'Pensamentos sobre os preconceitos morais', $O$ andarilho e sua sombra tratava de sentimentos morais, Humano demasiado humano examinava conceitos morais. O filósofo ocupava-se com conceitos, préjuízos, sentimentos em suas considerações sobre a moral e até podia empregar, eventualmente, o termo "valor" ou a expressão "apreciação de valor". Mas é a partir de Assim falava Zaratustra que passa a trabalhar com a noção de valor. Isso possibilita uma reorganização de seu pensamento: suas ideias são submetidas a nova articulação; seus escritos são por ele mesmo encarados segundo nova ótica, como deixam entrever os prefácios de 1886 aos livros já publicados e a autobiografia de 1888; suas reflexões sobre os valores e, em particular, os valores morais ganham nova consistência". MARTON, S. Nietzsche: das forças cósmicas aos valores humanos $-3^{\circ}$ ed. - Belo Horizonte: Editora. UFMG 2010, p. 86. 
Dias, G.

Em outras palavras, a relação que Clark estabelece entre Aurora e o projeto da transvaloração torna-se problemática na medida em que ela pressupõe que Nietzsche opera com noções não presentes no livro, como é o caso da noção de valor.

Outro comentador, David Owen, afirma que "a mudança de Nietzsche para o desenvolvimento de seu procedimento genealógico de investigação está situada dentro do projeto global da transvaloração dos valores que se inicia em Aurora" 5 . Se Clark não hesitou incluir o livro no projeto da transvaloração, Owen vai além ao interpretar Aurora à luz de textos posteriores (Para a genealogia da moral e Ecce homo) e defender que o livro representa uma virada metodológica, trazendo então em seu bojo o procedimento genealógico, não a partir da noção de valor, o que seria mais adequado, mas a partir de uma relação com a moralidade que já estaria presente em Aurora. Como ele mesmo comenta: “[é] em Aurora, como nos diz Nietzsche em Ecce homo, que a sua "campanha contra a moral começa' em uma 'transvaloração de todos os valores"” 6. Como veremos mais à frente, não foi bem isso o que Nietzsche afirmou. O filósofo quis dizer que Aurora, como o título sugere, é uma espécie de despontar de novas auroras em sua filosofia ou, em outros termos, que Aurora apresenta uma filosofia transitória.

A dificuldade que encontramos nessa leitura de Owen não está no fato de ele reconstruir o contexto de surgimento do projeto da transvaloração a partir de Aurora. O problema é que ele o faz sem muita cautela, ao pressupor que em Aurora Nietzsche já opera com o procedimento genealógico. A nosso ver, porém, a campanha de Nietzsche contra a moral realizada em Aurora ainda não está situada dentro do projeto da transvaloração, mas dentro de um projeto em que o filósofo busca um desprendimento e futura liberação dos preconceitos morais. Nesse sentido, em Aurora, Nietzsche ainda

5 OWEN, D. Nietzsche, Re-evaluation and the Turn to Genealogy. European Journal of Philosophy, 11:3. Blackwell Publishing Ltd, 2003, p. 249.

6 OWEN, D, 2003, p. 249.

236 I Cad. Nietzsche, São Paulo, n. 34 - vol. I, p. 231-254, 2014. 
não opera com o procedimento genealógico, nem tampouco com a noção de valor. Portanto, a dificuldade de Owen é que ele toma como pressuposto a ideia de que em Aurora Nietzsche já operaria com a noção de valor tal como irá fazer a partir de Assim falou Zaratustra. É desse ponto de vista que ele sugere a ideia de que Aurora marca uma virada na obra de Nietzsche, não apenas orientando-se, a partir daí, para o projeto da transvaloração de todos os valores, mas já como parte efetiva deste programa filosófico.

A nosso ver, o exame que Nietzsche realiza em Aurora, de fato, o levou a desmascarar os preconceitos subjacentes à moral, mas não a problematizar a moral em termos de valores. É o próprio Nietzsche, no prólogo de Para a genealogia da moral, quem nos autoriza a fazer essa diferenciação conceitual e metodológica. Para ele a noção de valor exigirá a necessidade "de uma crítica dos valores morais" de tal maneira que "o próprio valor desses valores deverá ser colocado em questão" (GM/GM, Prólogo 6, KSA 5.253). Portanto, diferentemente do que comentam Clark e Owen, queremos evidenciar que em Aurora Nietzsche realiza uma pesquisa da moral na qual ele não opera com a noção de valor, tampouco com o procedimento genealógico de investigação da moral, mas com ferramentas teóricas transitivas, em termos metodológicos denominamos esse procedimento investigativo de pré-genealógico.

III - O projeto filosófico de Aurora

O próprio Nietzsche, em Ecce homo, dedica, como fez a outros livros seus, um capítulo a Aurora, no qual delineia seu objetivo: refletir sobre os preconceitos morais. E também procura apresentar esse seu livro como uma primeira aurora (Morgen), ou seja, como um primeiro desprendimento e liberação dos preconceitos morais. O filósofo indica ou deixa entrever que uma nova aurora estava por vir, mais precisamente, aquilo que ele considerou ser o seu projeto da "transvaloração de todos os valores" (Umwerthung aller Werthe) 
Dias, G.

(EH/EH, Morgenröte 1, KSA 6.330). Desse ponto de vista, a partir do conjunto dos escritos de Nietzsche, Aurora pode ser compreendida, segundo a nossa hipótese, como uma obra portadora de uma filosofia transitória. E talvez por causa desse caráter de transitoriedade, tenha sido tão negligenciada, considerada obscura e sem uma posição claramente definida no corpus filosófico nietzschiano. Contudo, ao levar a cabo uma "campanha contra a moral", conjecturar sua gênese e pôr abaixo seus preconceitos, Aurora permitiu a Nietzsche criar os rudimentos necessários para a formulação de elementos filosóficos de transição.

O subtítulo do livro Aurora fixa bem o objeto empreendido: "pensamentos sobre os preconceitos morais". Portanto, tal como indicado já no início da obra, trata-se de realizar uma história exata (genaue Geschichte) do surgimento dos preconceitos morais (M/A, 1, KSA 3.19). Para tanto, o filósofo desenvolve uma espécie de método histórico-genético (ou, como preferimos definir, pré-genealógico) com o qual pretende investigar a história da emergência (Entstehung) da moral, mostrando, em seguida, o caráter historicamente condicionado da moralidade cristã. Desse modo, ele combate essa moral ao organizar e elucidar a procedência de seus preconceitos a partir da eticidade do costume, oposta ao modo de valorar altruísta cristão. As ambiguidades presentes no termo Entstehung reforçam a nossa proposta de que Aurora, em certo sentido, já transitava para o procedimento genealógico, mas ainda não o colocava realmente em prática, antes criava o cenário para que isso ocorresse em seguida, isto é, em obras posteriores.

O projeto do livro Aurora gira em torno da possibilidade futura de uma liberação e/ou desprendimento da visão moral da existência. Conforme afirma o filósofo, o "significado moral da existência" se baseia em preconceitos errôneos destinados a desaparecer (M/A, 3, KSA 3.19). Um desses erros estaria na crença de que existem ações morais puras, ou seja, o preconceito de acreditar que é possível ter o conhecimento exaustivo do que é uma ação moral (M/A, 116, KSA 3.110). Por isso, Nietzsche defende que "talvez não haja

238 I Cad. Nietzsche, São Paulo, n. 34 - vol. I, p. 231-254, 2014. 
agora nenhum preconceito melhor acreditado do que este: que se sabe o que constitui propriamente a moral" (M/A, 132, KSA 3.124). Em outras palavras, o projeto filosófico empreendido por Nietzsche em Aurora é alcançar certa liberação e/ou desprendimento dos preconceitos morais constituídos historicamente ao longo de milênios.

Ao propor uma superação dos erros e preconceitos da longa história moral humana, Nietzsche aponta para uma transição na sua filosofia. Isso porque tal tentativa de superação dos preconceitos morais mostra-se decisiva para a construção do procedimento genealógico posterior. Desse ponto de vista, é importante não menosprezar Aurora, uma vez que esse livro é decisivo para a construção de elementos filosóficos preliminares que possibilitarão o posterior desenvolvimento de um novo procedimento investigativo na filosofia nietzschiana.

IV - Transição no procedimento filosófico de investigação

No conjunto das obras de Nietzsche, Aurora apresenta não apenas uma mudança de objeto, mas uma transição quanto ao procedimento de investigação. Desde Humano, demasiado humano, Nietzsche se direciona cada vez mais para a investigação da moral por meio de reflexões sobre os sentimentos morais. Em Aurora, efetiva uma investigação e crítica dos preconceitos morais; mais do que uma simples pesquisa da história dos sistemas éticos, procura conhecer as condições e circunstâncias em que eles surgiram e se desenvolveram, empreendendo uma pré-genealogia sobre a instância originária dos juízos morais humanos.

Suas primeiras hipóteses sobre a gênese da moral remontam às obras Humano demasiado, humano I e II, Aurora e A gaia ciência ${ }^{7}$.

7 Chiara Piazzesi mostra a maneira pela qual Nietzsche constitui o procedimento genealógico ao interpretar o aforismo 14 d'A gaia ciência "como um exemplo de exercício pré-genealógico". A autora "tenta pôr em evidência as intenções analítico-críticas - quase sempre implícitas 
Dias, G.

Como ele mesmo indica: "meus pensamentos sobre a procedência de nossos preconceitos morais (...) receberam sua primeira, parcimoniosa e provisória expressão naquela coletânea de aforismos que leva o título Humano, Demasiado Humano" (GM/GM, Prólogo 2, KSA 5.251). E detalha: “(...) pela primeira vez apresentei as hipóteses sobre origens (...) ainda sem liberdade, sem linguagem própria para essas coisas próprias, e com recaídas e hesitações diversas" (GM/GM, Prólogo 4, KSA 5.252). É nesse sentido metodológico que, a nosso ver, o procedimento filosófico empregado por Nietzsche à pesquisa da moral, especificamente em Aurora, pode ser considerado como uma espécie de investigação pré-genealógica ${ }^{8}$.

A diferença básica entre o procedimento pré-genealógico e a genealogia da moral propriamente dita é a seguinte. $\mathrm{O}$ raciocínio pré-genealógico visa a desvendar a gênese da moral. Para tanto, emprega-se uma pesquisa histórico-genética na qual as ciências, tais como a história, a psicologia, a antropologia, a filologia, a fisiologia são utilizadas para investigar a procedência dos sentimentos e preconceitos morais. $\mathrm{O}$ objetivo principal da investigação pré-genealógica são os pré-juízos morais, a história da cultura, os sentimentos morais, a paixão pelo conhecimento, o sentimento de potência etc.

De modo diferente, a genealogia da moral se depara com a problemática do valor dos valores, desenvolvida somente a partir de Assim falou Zaratustra e mais particularmente em Para a genealogia da moral.

- e os pressupostos de FW/GC 14, KSA 3.356, que permitem olhar o aforismo como um exercício preparatório para uma prestação genealógica". PIAZZESI, C. "Was Alles Liebe genannt wird": FW/GC 14, KSA 3.356 como exemplo de exercício pré-genealógico, in Cadernos Nietzsche 27, 2010, p. 96.

8 Tal como salienta Blaise Benoit, em Aurora a abordagem nietzschiana da moral segue "uma perspectiva pré-genealógica que seria a de desmistificação, ou seja, a retradução do espírito em corpo, isto é, em realidades fisiopsicológicas o que são pulsões". BENOIT. B. Du volontarisme moral à l'autorégulation des pulsions? Quelques remarques à propos d'Aurore, $\$ 109$, V Congresso do GIRN, 20012. 
Já de acordo com o raciocínio pré-genealógico, os preconceitos morais são compreendidos enquanto condições básicas de conservação; instituídos de um ponto de vista incondicional, onde reina a obediência moral como lei superior. Desse ponto de vista, os problemas fundamentais da história humana ocidental são morais, revelados na investigação da proveniência dos pré-juízos e erros intelectuais constituintes dessa história. É nessa direção que, em Aurora, Nietzsche desenvolve um projeto que procura alcançar uma liberação e/ou desprendimento dos preconceitos morais para a humanidade futura, por meio de uma investigação, podemos dizer, pré-genealógica.

Seguindo esse raciocínio, podemos dizer que a pesquisa pré-genealógica dos preconceitos morais empregada em Aurora começa com uma reflexão sobre os primórdios da moral, a eticidade do costume (Sittlichkeit der Sitte) (M/A, 9, KSA 3.21-24) ${ }^{9}$. Tal pesquisa é que permitiu a Nietzsche certo trânsito para outras experiências metodológicas de investigação sobre a moral. Desse modo, a investigação pré-genealógica realizada em Aurora ocupa uma função específica e estratégica. Ela constitui um momento de

90 termo Sittlichkeit der Sitte possui diferentes traduções. Na francesa de Julien Hervier, 1989, consta moralité des moeurs; encontra-se em italiano costumatezza del costume, em inglês morality of mores e morality of custom, em espanhol eticidad de la costumbre, em português moralidade do costume. Rubens Rodrigues T. Filho traduz por eticidade do costume e acrescenta que "Eticidade ou moralidade, duas palavras que perderam a referência ao significado original de costume, que têm por base (ethos em grego, mos em latin). O texto alemão, ao dizer Sittlichkeit der Sitte, o evoca muito mais diretamente - é que a língua não perdeu totalmente a memória dessa ligação, tanto que ética se diz Sittenlehre (doutrina dos costumes) e já Kant reservava a fundamentação da moral para uma "metafísica dos costumes" (Col. "Os Pensadores"; 1996, p, 141). Tom Bailey considera que Nietzsche, mesmo empregando "a palavra 'sittlich', ao invés de 'moralisch', para "moral", não implica que ele considere ser o "indivíduo soberano" livre apenas da primitiva "moral do costume [Sittlichkeit der Sitte]", sob a qual ele alega que a atividade se desenvolve, e nem da moral moderna, à qual ele geralmente se refere como "Moral" ou "Moralität". BAILEY, T. As abordagens de Nietzsche acerca da epistemologia e da ética kantianas, in Cadernos Nietzsche, $n^{\circ}$ 29, Volume II. São Paulo: GEN, 2011. Adotamos a tradução de Rubens R. T. Filho, por considerar que eticidade do costume faz referência às investigações de Nietzsche sobre a gênese da moral, algo diferente da moralidade (moralität) moderna cristã. 
Dias, G.

transição no procedimento filosófico de investigação no conjunto dos escritos de Nietzsche. Nesse caso, trata-se da construção de um quadro teórico que contribuirá o filósofo transitar para outras experiências de pensamento, ou, como ele mesmo sugere, para novas auroras em sua filosofia (EH/EH, Morgenröte 1, KSA 6.330).

Em outros termos, com o intuito de investigar a gênese da moral, Nietzsche emprega primeiramente um procedimento que se pode chamar de pré-genealógico, o qual opera com a noção de preconceitos morais e é decisivo para posteriormente desenvolver a pesquisa genealógica e trazer à luz o problema do valor dos valores. Ao colocar a moral como problema, Nietzsche foi capaz de evidenciar os preconceitos morais dos filósofos e, por conseguinte, realizar uma tentativa de desprender o mundo da significação moral que lhe foi atribuída, para então, finalmente, poder alcançar as condições que viabilizou o desenvolvimento do problema do valor dos valores. Aurora, portanto, traz uma ampla pesquisa sobre a moral, mas não ainda uma genealogia da moral. Entretanto, sua abordagem dos preconceitos morais serviu como um momento de trânsito, de construção e viabilização de noções filosóficas futuras.

$\mathrm{E}$ assim, nesta fina fluidez de pensamentos, quem não se atenta para o caráter transitório da filosofia desenvolvida por Nietzsche em Aurora pode interpretar essa obra como uma espécie de filosofia de fachada. Para Heidegger Aurora seria apenas uma filosofia de fachada, no sentido de que ele defende a ideia de que “[o] que o próprio Nietzsche publicou na sua época criativa foi sempre somente um primeiro plano (...). A autêntica filosofia de Nietzsche ficou relegada como "obra póstuma" ${ }^{10}$. Segundo Heidegger a verdadeira filosofia de Nietzsche não está contida nas obras publicadas, mas nos póstumos. Em certa medida, para corroborar com tal compreensão, o filósofo da floresta negra poderia se apoiar

10 HEIDEGGER, M., Nietzsche I. Trad. Juan L. Vermal. Madrid: Destino, 2000, p. 24.

242 | Cad. Nietzsche, São Paulo, n. 34 - vol. I, p. 231-254, 2014. 
na passagem em que Nietzsche discorre a respeito do que chama de "filosofia-de-fachada" (Vordergrunds-Philosophie), (JGB/BM, 289, KSA 5.234).

No entanto, dessa maneira a leitura de Heidegger deprecia e negligencia as obras publicadas; o que ocorreu justamente com $\mathrm{Au}$ rora por algum tempo, não porque Nietzsche não teria apresentado nesse livro mais do que uma filosofia de fachada, mas porque $\mathrm{Au}$ rora é portadora de uma filosofia transitória em seu pensamento. Além disso, seria uma interpretação precipitada considerar que as obras publicadas de Nietzsche trazem uma filosofia definitiva. Parece-nos que não há uma filosofia estática em Nietzsche, antes se poderia dizer que há uma filosofia em constante transformação, em transito, no sentido de que o próprio filósofo nunca pretendeu alcançar verdades últimas, mas reconheceu a inesgotabilidade da tarefa filosófica, e isso o livro Aurora mostra muito bem, basta, para tanto, que consideremos o aforismo Nós, aeronautas do espírito! (M/A, 575, KSA 3.331), por exemplo.

Esse aforismo e, de modo geral o conjunto dos escritos de Nietzsche, expressam um pensamento movente, se construindo, transitando entre diferentes e contraditórias ideias. Aurora apresenta bem esse caráter inacabado do pensamento de Nietzsche, um pensamento que tem a consciência de que irá navegar por muitos mares, mas que seu destino é naufragar no infinito (M/A, 575, KSA 3.331).

\section{$V$ - Do sentimento de potência à Vontade de potência}

O que Nietzsche denomina por sentimento de potência pode ser tomado como a instância sintetizadora da pluralidade dos impulsos constitutivos da moral e, assim, como um dado filosófico decisivo para a uma transição na sua filosofia. Empregado enquanto critério para criticar a moral, o sentimento de potência, a nosso ver, permite a Nietzsche interpretar, de um lado, a antiga eticidade do costume, alicerçada no sentimento da eticidade e na 
Dias, G.

incondicionalidade da obediência, e, de outro, a moderna moralidade (moralität) cristã, sustentada na intensificação da sensação de potência individual. A partir disso, o filósofo considera que noções como bom e mau, deveres, direitos, a felicidade, podem ser caracterizadas enquanto expressões do sentimento de potência. Enquanto dado teórico novo, à luz de obras posteriores, o sentimento de potência mostra-se como um elemento filosófico de transição no pensamento de Nietzsche, já que ele contribui para a construção da doutrina da vontade de potência.

O autor de Aurora compreende que as instâncias culturais de uma sociedade cumprem a função de intensificar o sentimento de potência dos seres humanos. Afirma que “o sentimento de potência desenvolveu-se com tal sutileza, que nisso o homem pode hoje rivalizar com a mais delicada balança. Tornou-se a sua mais forte inclinação (...)" (M/A, 23, KSA 3.35, trad. PCS, modificada). Nenhuma moral, arte ou ciência, nenhuma instância da cultura constitui-se como um fim em si mesmo, devendo sempre, antes de tudo, contribuir à intensificação do sentimento de potência dos homens.

É por diferentes motivos que defendemos que Aurora apresenta uma filosofia transitória. Por exemplo, o livro traz elementos filosóficos que permitirão a Nietzsche transitar para novas maneiras de investigação, a focar mais especificamente a moral como problema, e é nesse livro que o filósofo apresenta pela primeira vez o conceito em questão. $\mathrm{O}$ que Nietzsche nomeia por sentimento de potência pode ser compreendido como um critério de crítica da moral e, enquanto tal, como algo novo em sua filosofia. Com esse conceito ele apresenta uma maneira particular de refletir sobre a moral, podendo então expressar o que subjaz e o que verdadeiramente impele os homens às ações ditas morais. Com o sentimento de potência, portanto, Nietzsche pôde então combater os objetivos morais humanos estabelecidos. A expressão expressa à instância de refinamento dos impulsos, do adestramento e interiorização das pulsões formadoras da sociabilidade humana. Além disso, também traz a dimensão psicológica e fisiológica da criteriosa análise de Nietzsche à moral em Aurora. 
Fisiológica no sentido de que os instintos, impulsos, sentimentos, inclinações e afetos são, por assim dizer, variantes lexicais que expressam, em suma, o sentimento de potência dos homens. Em outras palavras, segundo o contexto referente à noção de fisiologia, para Nietzsche os "nossos juízos morais e valorações são apenas imagens e fantasias baseadas em processos fisiológicos por nós desconhecidos" (M/A, 119, KSA 3.114).

Assim, a eticidade do costume representa um primeiro momento de contenção e controle moral das pulsões e instintos humanos. Em seguida, a moralidade cristã, de outro modo, amplia ainda mais o domínio sobre os impulsos, tornando possível o refinamento da crueldade enquanto virtude e moral da distinção (M/A, 30, KSA 3.39). Se na eticidade do costume a intensificação do sentimento de potência individual só era possível por meio da obediência incondicional à norma, a lei, ou seja, ao costume; na moralidade cristã, ocorre justamente o questionamento da norma, somente por meio dessa via será possível ao indivíduo alcançar o máximo de sentimento de potência.

Trata-se aqui da crítica nietzschiana à eticidade do costume e aos preconceitos morais cristãos. Para tanto, Nietzsche mostra que o advento da moralidade cristã demarca o momento em que a potência individual passa a vigorar como a condição indispensável de transformação e criação de novos preconceitos morais, constitutivos da sobrevivência comunitária. Seria pertinente interpretar que com Aurora Nietzsche se propunha a refletir sobre uma liberação e/ou desprendimento dos preconceitos morais cristãos, abrindo caminho para uma nova maneira de conceber a moral e a religião, destituída de preconceitos prejudiciais como o desprezo ao corpo enquanto algo inferior à alma, considerada imortal. Com isso, ele estaria desvendando a moralidade da renuncia de si, e desde já também defendendo a possibilidade futura da criação de novos valores, capazes de afirmar a vida terrena em oposição à moralidade transcendente até então vigente no ocidente cristão. 
Dias, G.

Aurora apresenta uma filosofia transitória na medida em que o sentimento de potência pode ser visto como sondagens preambulares que irão desembocar em algo característico da filosofia tardia de Nietzsche. A expressão sentimento de potência, enquanto critério de análise crítica dos sentimentos e preconceitos morais indica o despontar de novas auroras na filosofia de Nietzsche, seja, por exemplo, no sentido de evidenciar-se como uma espécie de proto-conceito da doutrina da vontade de potência ${ }^{11}$.

No entanto, qual seria, afinal, a diferença fundamental entre sentimento de potência (Gefiuhl der Macht) e vontade de potência (Wille zur Macht)? Este último termo é, sem dúvida, mais pretencioso e filosoficamente mais abrangente, busca nada menos do que decifrar todo o texto da realidade-aparência (conforme o $\S 36$ de Para além de bem e mal, JGB/BM, KSA 5.54) ${ }^{12}$. Já o primeiro, por sua vez, está mais focado em traduzir as ações ditas morais, as estimativas, sentimentos e preconceitos morais em estados naturais, pulsionais, em remeter a procedência da moralidade para a obediência irrefletida, para os afetos, impulsos, instintos. Isto é, a insaciável apetite de potência dos homens se revela, num primeiro momento, na pré-histórica época denominada eticidade do costume, por meio das pulsões, a crueldade, o impulso de domínio; e na moralidade cristã, de outro modo, o sentimento de potência atinge certa "espiritualização" (Durchgeistigung) gerada pelo sentimento de submissão, quando "depois que um ponderado modo de vida domou o animal que há no homem" (M/A, 60, KSA 3.59).

11 Nesse ponto estamos em acordo com Deleuze, ele diz que "Nietzsche, antes mesmo de ter elaborado o conceito de vontade de poder e de lhe ter dado toda a sua significação, falava já num sentimento de poder: o poder foi tratado por Nietzsche como caso de sentimento e de sensibilidade, antes de o ser como um caso de vontade". DELEUZE, G. Nietzsche e a filosofia. $2^{\circ}$ ed, Rés-Editora, Portugal, 2001, p. 95.

12 Ver também a interpretação de Wotling, ele mostra que Nietzsche, com a hipótese da vontade de potência, tornou legível a tentativa de "decifrar o texto da realidade-aparência". WOTLING, P. Nietzsche o problema da civilização, trad. Vinicius de Andrade. 1. Ed. - São Paulo: Editora Barcarolla, 2013, p. 89. 
Apoiado no sentimento de potência Nietzsche julga que "nós" somos menos simples do que os Gregos, e assevera que na verdade "nós" somos mais nobres do que eles pelo nosso sentido da honra e das virtudes cavalheirescas, enquanto eles não sabiam o que fazer com toda a sua insaciável apetite de potência. Somos mais inclinados à "boa reputação (honra) do que a conquista de um nome ruim, quando este se concilia com a fama e o sentimento de potência" (M/A, 199, KSA 3.173, trad. PCS, modificada). Os Gregos manifestavam seu sentimento de potência, ao passo que o homem "cavalheiresco e feudal" espiritualiza seu apetite de potência "num jogo de honra" e, ao contrário daquele, por aventura e falta de seriedade à vida a coloca em risco em duelos.

No livro Aurora, portanto, Nietzsche apresenta elementos filosóficos capazes de iniciar uma nova maneira de abordar a moral. Essa nova maneira evidencia o quanto a história da moral é construída por continuas transformações nos modos de agir e avaliar dos homens. A fim de compreender essa nova abordagem da moral e localizar a posição dessa obra no conjunto dos escritos nietzschianos, a expressão sentimento de potência pode nos auxiliar a compreender em que sentido Nietzsche já opera neste livro uma criteriosa crítica dos preconceitos morais, capaz de contribuir para o aparecimento de novas experiências de pensamento em sua filosofia. De certa maneira, podemos afirmar que o sentimento de potência, tal como aparece pela primeira vez em Aurora, será decisivo para que dele Nietzsche possa transitar e viabilizar a hipótese da vontade de potência, tal como aparece em Para além de bem e mal $(\mathrm{JGB} / \mathrm{BM}, 36, \mathrm{KSA} 5.54)^{13}$.

13 "Pode-se, consequentemente, considerar Aurora como um teste último, um ensaio geral antes que a vontade de potência seja proclamada como princípio fundamental do pensamento de Nietzsche". Ver KAUFANN, Walter (1974), Nietzsche, Philosopher, Psychologist, Antichrist. Princeton: Princeton University p. 161. 
Dias, G.

\section{VI - Da transmutação da moral a transvaloração dos valores}

Nietzsche compreende o cristianismo como uma transmutação (Verwandlung) moral da eticidade do costume (M/A, 72, KSA 3.67) ${ }^{14}$. Enquanto transmutação da maneira costumeira de agir e avaliar dominantes, o cristianismo, mais do que uma religião, constitui-se como um fenômeno moral. Nesse sentido, Aurora apresenta-se também como uma filosofia transitória no sentido de propiciar o despontar de um programa filosófico novo na filosofia de Nietzsche, qual seja a transvaloração de todos os valores, pois, com a transmutação da eticidade do costume em moralidade cristã, o filósofo trouxe em sua obra subjacentemente, pela primeira vez, a ideia de "transvalorar".

O cristianismo, segundo Nietzsche, constitui-se enquanto uma inversão da lógica moral da eticidade do costume. Essa transmutação moral ocorrida no domínio da eticidade do costume (inclua-se aqui o que Nietzsche nomeia de valores nobres antigos) para a moralidade cristã é abordada amplamente em Aurora enquanto inversão de preconceitos morais. E, nesse sentido, antecipadamente indica o que em Para além de bem e mal será denominado como "uma transvaloração de todos os valores antigos" (JGB/BM, 46, KSA 5.66) ${ }^{15}$.

14 Os vocábulos Verwandlung e Umwerthung podem ser confundidos na medida em que o segundo fora primeiramente traduzido de modo inapropriado por transmutação (por Florestan Fernandes, no texto Nota sôbre Frederico Nietzsche, publicado na Folha da Manhã, em 1944; e por Antonio Candido, que publicou em 1946, no Diário de São Paulo "O Portador", provavelmente esses autores foram influenciados pela tradução portuguesa ou pela antiga tradução francesa de Henri Albert; o texto de Antonio Candido foi publicado nos Cadernos Nietzsche 32; o Editor da revista fez grande esforço para também publicar o texto de Florestan Fernandes, mas não obteve sucesso devido às questões envolvendo direitos autorais); Paulo César de Souza traduz Umwerthung por tresvaloração, justifica que "tres é uma variante de trans, que transmite a ideia de "movimento para além ou através de" (1995, p. 120). Contudo, a confusão é desfeita por Rubens Rodrigues Torres Filhos, ele traduz Verwandlung por transmutação e Umwerthung por transvaloração.

15 Em seu estudo comparativo das obras Humano, demasiado humano e Para além de bem e mal, Itaparica aponta que essas obras se complementam, no sentido de que "as questões

248 I Cad. Nietzsche, São Paulo, n. 34 - vol. I, p. 231-254, 2014. 
De forma inovadora, em Aurora Nietzsche passa a compreender o cristianismo como um fenômeno moral ${ }^{16}$. Tal identificação é estabelecida na medida em que ele interpreta que "o cristianismo converteu-se num brando moralismo" (M/A, 92 KSA 3.82). Nessa senda, entende que a moralidade substituiu a religião enquanto normatividade, e que a ciência, por sua vez, tende a cada vez mais colocar-se em seu lugar (M/A, 10, KSA 3.24) ${ }^{17}$.

$\mathrm{O}$ ponto em questão é que o cristianismo desenvolve e consolida uma profunda transformação moral iniciada com Sócrates ${ }^{18}$. Ela se contrapõe diametralmente à eticidade do costume, para a qual toda ação individual está sempre orientada para o fortalecimento das normas da comunidade, onde cada indivíduo age de acordo com os costumes estabelecidos (M/A, 9, KSA 3.21-24).

sobre a moral formuladas na década de 70 estarão inseridas da década de 80 e no projeto global da transvaloração de todos os valores". ITAPARICA, A. Nietzsche: estilo e moral. SP, Ijuí. Editora UNIJUÍ, 2002, p. 21. De fato, a moral empresta unidade à filosofia de Nietzsche; em todo caso, a leitura de cada obra em seu tempo próprio sempre irá apontar para transições, uma vez que o procedimento de análise da moral que o filósofo realiza é diferente em cada uma das obras.

16 "A compreensão nietzschiana do cristianismo como um fenômeno moral mostra-se na relevância dada à "ideia de castigo", assim como se mostra também na ideia de compaixão". In MÜLER-LAUTER, W. Nietzsche: sua Filosofia dos Antagonismos e os Antagonismos de sua Filosofia. Trad. de Claudemir Araldi. SP: Editora UNIFESP, 2009, p. 161. Esses dois conceitos são amplamente trabalhados em Aurora, o primeiro aludindo à religião e à moral e o segundo se relaciona ao cristianismo e a fundamentação da moral sistematizada por Schopenhauer.

17 Isso mostra o quanto no livro Aurora Nietzsche já tinha em mente teses que serão desenvolvidas em A gaia ciência e em Para a genealogia da moral; algo semelhante ao fragmento póstumo escrito à época de Aurora, onde se lê: "as ciências representam a moral superior em relação aos decodificadores de enigmas e construtores de sistemas: moderação, justiça, sobriedade, o humor pacífico, bravura, paciência, simplicidade, concisão etc." (Nachlass/FP 4 [295]). Ver Le refus du sytème, WOTLING, P., La philosophie de l'esprit livre, Introduction à Nietzsche. Paris: Éditions Flammarion, 2008, p. 124. Esse texto alude aos interlocutores de Nietzsche em Aurora: os filósofos sistematizadores, sempre preocupados em fundamentar a moral seja à razão como quer Kant ou à compaixão como faz Schopenhauer.

18 Segundo Stegmaier, "Nietzsche rivalizou sobretudo com Sócrates, a quem, como pretendia denunciar, a "moral cristã" devia fundamentalmente sua força persuasiva". In STENGMAIER, W. A transvaloração de Nietzsche como destino da filosofia e da humanidade? (Ecce homo, Por que sou um destino). In: SILVA JR, I. (Org.) Filosofia e cultura: festschifr em homenagem a Scarlett Marton. São Paulo: Editora Barcarolla, 2011, p. 196. 
Dias, G.

Segundo o raciocínio de Nietzsche, o cristianismo diferencia-se completamente da eticidade do costume, promovedora da obediência à tradição e, por conseguinte, inversa à cristandade, fomentadora de uma moralidade menos comunitária e mais individualista, privada, pessoal e interiorizada.

Em Aurora, ao abordar a eticidade do costume, Nietzsche mostra que nela o sofrimento, a crueldade, a privação e a vingança eram tidos como virtudes, viabilizavam o fortalecimento da comunidade e predomínio do homem ético (M/A, 18, KSA 3.29). Já o bem-estar, a felicidade individual, a compaixão eram repudiadas, compreendidas como imorais por causa da ameaça que trariam para a comunidade. Nesse sentido, em relação à eticidade, colocar a compaixão como princípio da ação implica cair numa transmutação moral, numa profunda transformação dos modos de agir, de viver, de criar. Por isso é que o cristianismo, segundo Nietzsche, realizou uma transmutação moral, enfraqueceu a potência do costume em favor do predomínio de uma moralidade que promove a intensificação não do sentimento da eticidade, mas do sentimento de potência do indivíduo. Essa transmutação moral, como se pode ver, já prenuncia o que Nietzsche viria a conceber apenas depois, no seu projeto de transvaloração de todos os valores.

$\mathrm{E}$ ao constatar essa transmutação moral que o cristianismo realizou frente à eticidade do costume, Nietzsche propõe uma libertação de toda imputação moral da existência. Com o propósito de tentar interpretar a existência despreconceituadamente, Aurora permitiu ao filósofo o despontar de novas auroras, isto é, transitar para novas experiências filosóficas. Ele acreditava, acima de tudo, que muitas auroras não brilharam ainda, em outras palavras, buscava libertar-se dos preconceitos morais milenares que depreciam o mundo, o diminuem e o empobrece, em troca de um olhar mais livre, despido de toda a visão moral que lhe foi impregnada ao longo de milênios.

250 I Cad. Nietzsche, São Paulo, n. 34 - vol. I, p. 231-254, 2014. 


\section{VII - Conclusão}

Assim, a despeito de alguns comentadores, não faz sentido inserir Aurora como parte integrante do projeto da transvaloração de todos os valores. Para encontrar seu lugar no contexto da filosofia nietzschiana, consideramos coerente interpretar essa obra como portadora de uma filosofia transitória, no sentido de construção das condições de possibilidade teórica que permitirão a Nietzsche alcançar à concepção de uma transvaloração de todos os valores vigentes até então no ocidente cristão. Aurora mostra-se, portanto, como uma filosofia transitória, ao apresentar elementos filosóficos decisivos para a consolidação de ferramentas teóricas necessárias à realização desse projeto no horizonte da filosofia madura de Nietzsche.

Além disso, uma breve reflexão sobre a expressão transvaloração de todos os valores nos permite verificar certa relação com Aurora geralmente desconsiderada pelos comentadores. Pode-se pensar que a expressão não deixa dúvida quanto à centralidade da noção de valor. Quanto à sua extensão conceitual, também indica não se limitar a transvalorar valores apenas morais, mas todos os valores, tais como os valores religiosos, epistemológicos e filosóficos etc. Nesta expressão, portanto, a noção de valor aparece com uma conotação completamente diferente daquelas utilizadas em obras anteriores a Assim falou Zaratustra. A partir desta obra a noção ganha uma nova e ampla significação, e, nesse sentido, o projeto da transvaloração de todos os valores encontra-se estreitamente ligado ao emprego ressignificado da noção de valor. Por isso, sempre que os comentadores relacionam Aurora ao projeto da transvaloração sem levar em consideração a importância da noção de valor, tendem a obscurecer o conteúdo dessa obra e a desconsiderar seu caráter de filosofia transitória.

$\mathrm{Na}$ Nietzsche-Forschung atual é comum encontrarmos o conceito de valor considerado sob um ponto de vista específico, ou seja, caracterizado em termos de condições de vida e relacionado 
Dias, G.

ao âmbito do projeto da transvaloração de todos os valores e da vontade de potência. De acordo com Marton, "[o] período da transvaloração dos valores tem fortes razões para ser assim denominado: é nele que se torna operatório a ideia de valor" ${ }^{19}$.

Portanto, em oposição à inclusão de Aurora como parte do projeto da transvaloração, nossa análise mostra que tal pretensão não se coaduna com o conteúdo e os objetivos do livro. Com efeito, no capítulo de Ecce homo dedicado ao livro, Nietzsche identifica seu projeto da transvaloração de todos os valores com uma nova aurora que começava a despontar a partir de Aurora. Isto é, o livro seria antes uma primeira manhã, uma transição, um desprendimento inicial dos preconceitos morais, para em seguida desembocar no projeto da transvaloração. Livro no qual, de fato, Nietzsche já constatava a existência de uma transmutação da moral, mas ela não opera com a noção de valor, mas com a noção de preconceitos morais.

Enfim, enquadrar Aurora como parte do projeto da transvaloração não contribui para a sua compreensão, ao contrário, na medida em que impõe conceitos e noções que o livro não aborda, acaba por obscurecê-lo. Associar literalmente Aurora ao projeto da transvaloração não favorece a uma compreensão dessa obra, antes a coloca fora de seu eixo reflexivo: os preconceitos morais. Aurora é uma obra de transição no pensamento de Nietzsche, mas é também uma obra independente, uma vez que possui seu próprio projeto filosófico. Mas isso somente pode ser vislumbrado quando o livro é lido em seu tempo próprio, sem ser submetido ao antes e o depois, quando interpretado à luz de seu empreendimento filosófico que, no caso, foi capaz de direcionar seu autor a transitar para novas experiências de pensamento.

19 MARTON, S. Nietzsche: das forças cósmicas aos valores humanos $-3^{\circ}$ ed. - Belo Horizonte: Editora. UFMG, 2010, p.86. 


\begin{abstract}
In this article, we aim to examine the hypothesis that the book Daybreak, in all the writings of Friedrich Nietzsche, presents a transitional philosophy. In this sense, we will see that, precisely because of its transitory Daybreak has been so overlooked and overshadowed, especially when commented not from their transitive theoretical framework, but from concepts and later projects.

Keywords: Daybreak - transition - pre-genealogy - feeling of power transmutation of morality
\end{abstract}

\title{
referências bibliográficas
}

1. AZEREDO, V., e SILVA JR, I. (Org.) Nietzsche e a interpretação. 1ed. -Curitiba, PR: CVC - Coleção Nietzsche em Perspectiva (Vol. 1) - coedição: São Paulo, SP: Humanitas, 2012.

2.

Eticidade do costume: a inscrição do social no homem. Dissertatio (UFPeI), v. 25, p. 73-89, 2007.

3. BENOIT, B. Du volontarisme moral à l'autorégulation des pulsions? Quelques remarques à propos d'Aurore, \$109. In: Lisboa, V Congresso do GIRN, quinta-feira, 21 junho de 2012.

4. BAILEY, T. As abordagens de Nietzsche acerca da epistemologia e da ética kantianas. In: Cadernos Nietzsche 29, Volume II. São Paulo: GEN, 2011.

5. CLARK, M. Daybreak: thoughts on the prejudices of morality. Trad. R. J. Hollingdale. Cambridge University Press, 1997.

6. CANDIDO, A. O Portador. In: Cadernos Nietzsche 32, São Paulo: GEN, 2013.

DELEUZE, G. Nietzsche e a filosofia. Trad. António M. Magalhães $2^{\circ}$ ed., Rés-Editora. Portugal, 2001.

7. FERNANDES, F. Nota sôbre Frederico Nietzsche, in http://almanaque.folha.uol.com. br/leituras_11jul00.htm, 1944.

8. HEIDEGGER, M., Nietzsche I. Trad. Juan L. Vermal. Madrid: Destino, 2000.

MARTON, S. Nietzsche: das forças cósmicas aos valores humanos $-3^{\circ}$ ed. - Belo Horizonte: Editora. UFMG, 2010.

9. MÜLER-LAUTER, W. Nietzsche: sua Filosofia dos Antagonismos e os Antagonismos de sua Filosofia. Trad. de Claudemir Araldi. São Paulo: Editora UNIFESP, 2009.

10. NIETZSCHE, F. Sämtliche Werke. Kritische Studienausgabe (KSA). Organizada por Giorgio Colli e Mazzino Montinari. Berlim : Walter de Gruyter \& CO., 1988. 15 v. 
Dias, G.

11. Obras incompletas. Trad. Rubens Rodrigues Torres Filho. São Paulo: Nova Cultural, 1996 (Col. "Os Pensadores").

12. ___ Aurore: pensées sur les préjugés moraux. Trad. Éric Blondel, Ole Hansen-

Løveet Théo Leydenbach; introdução, notas, cronologia e bibliografia de Éric Blondel. Paris: Flammarion, 2012.

13. Aurore: réflexions sur les préjugés moraux. Trad. Henri Albert. Paris: Mercure de France, 1901.

14. ___ Aurora: pensieri sui pregiudizi morali. Trad. Emma Sola. Milano: editora Fratelli Bocca, 1946.

15. __ Aurore: Pensées sur les préjugés moraux. Trad. Julien Hervier. Paris: Editions Gallimard, 1989.

16. ___ Aurora: reflexões sobre os pensamentos morais. Trad. Paulo César Souza. São Paulo: Companhia das Letras, 2004.

17. Ecce homo: como alguém se tonar o que é. Trad. Paulo César Souza. São Paulo: Companhia das Letras, 1995.

18. __ Genealogia da moral: uma polêmica. Trad. Paulo Cesar de Souza - São Paulo: Companhia das Letras, 1998.

19. OWEN, D. Nietzsche, Re-evaluation and the Turn to Genealogy. European Journal of Philosophy, 11:3, p. 249-272. Blackwell Publishing Ltd, 2003.

20. PIAZZESI, C. "Was Alles Liebegenannt wird": FW/GC 14, KSA 3.356 como exemplo de exercício pré-genealógico. In: Cadernos Nietzsche 27: GEN, 2010.

21. ITAPARICA, A. Nietzsche: estilo e moral. São Paulo: Discurso Editorial; Ijuí: Editora UNIJUÍ, 2002.

22. KAUFANN, W. Nietzsche, Philosopher, Psychologist, Antichrist. Princeton: Princeton University, 1974.

23. STENGMAIER, W. A transvaloração de Nietzsche como destino da filosofia e da humanidade? (Ecce homo, Por que sou um destino). In SILVA JR, I. (Org.) Filosofia e cultura: festschifr em homenagem a Scarlett Marton. São Paulo: Editora Barcarolla, 2011.

24. WOTLING, Patrick. La philosophie de l'esprit livre, Introduction à Nietzsche. Paris: ÉditionsFlammarion, 2008.

25. Nietzsche o problema da civilização. Trad. Vinicius de Andrade. $1^{\circ}$. Ed. - São Paulo: Editora Barcarolla, 2013.

Artigo recebido para publicação em 13/05/2013. Artigo aceito para publicação em 20/06/2013.

254 | Cad. Nietzsche, São Paulo, n. 34-vol. I, p. 231-254, 2014. 